\title{
Termik Santral Küllerinde Yanmamış Karbonun Pulverize Kömür Boyut Dağılımı ve Uçucu Madde İçeriği ile İlişkisi
}

\author{
Mehmet BILLEN*, Serdar YILMAZ \\ Bülent Ecevit Üniversitesi, Maden Mühendisliği Bölümü, Zonguldak \\ (ORCID: 0000-0003-0960-9421) (ORCID: 0000-0003-0249-1600)
}

\begin{abstract}
Öz
Bu çalışmada, iki termik santral özelinde uçucu küller yanmamış karbon açısından incelenmiş ve elde edilen analiz sonuçları kömürün kısa analiz sonuçlarıyla ve kömürün öğütülme sonrası boyut parametreleriyle karşılaşıırılmıştır. İncelenen ilk santral için, yanma kazanının aynı şartlar altında farklı kömür örnekleriyle çalıştığı bir süreç incelenirse ve bu süreçte küllerde farklı değerlerde yanmamış karbon tespit edilirse, bunun nedeninin daha çok kömüre ait nedenler olduğu düşünülebilir. Bu çalışmada, iki farklı santral değerlendirilmiş olup, 17 farklı uçucu madde içeriği olan kömür kullanan birinci santralde gözlemlenen 17 farklı yanmamış karbon değerinin ilişkisi kurulmuş ve sonuçlar kömürün uçucu madde içeriğinin yanmamış karbon üzerinde oldukça etkili olduğunu göstermiştir. İkinci santralde ise pulverize kömür örneklerinin boyut dağılımları incelenmiş ve boyut parametreleriyle yanmamış karbon arasındaki ilişkiler belirlenmiştir. Kömür boyut dağılımına ait $\mathrm{D}_{32}$ boyut parametresinin yanmamış karbon ile ilişkisinin anlamlı olduğu sonucuna varılmıştır.
\end{abstract}

Anahtar kelimeler: Yanmamış karbon, Kömür, Boyut parametreleri, Termik santral, Uçucu madde.

\section{The Relationship of Unburned Carbon in Coal fired Power Plants with Pulverized Coal Size Distribution and Volatile Matter Content}

\begin{abstract}
In this study, considering two specific coal fired power plants, fly ash samples were analyzed in terms of unburned carbon and amount of unburned carbon in these samples were compared to coal proximate analysis results and the size parameter results of coal samples after grinding. For the first power plant under investigation, if a period of same conditions of same boiler utilization of different types of coals considered, and if different amounts of unburned carbon is observed in fly ashes in that specific period, the reason behind either high or low amount of unburned carbons can be explained mainly by coal related factors. In this study, two different coal fired power plant were investigated and regarding the first one, 17 utilized coal type with different volatile matter content and their corresponding unburned carbon in ash is plotted and the obtained correlation between coal volatile matter and unburned carbon in ash showed that volatile matter content of coal is dominantly affecting the coal burnout. Regarding the second coal fired power plant investigated, pulverized coal samples collected are analyzed in terms of their size distribution and relationships between size parameters and unburned carbon were determined. It was concluded that, $\mathrm{D}_{32}$ size parameter shows one of the better relation between unburned carbon among other size parameters.
\end{abstract}

Keywords: Unburned carbon, Coal, Size Parameters, Power plant, Volatile matter

\section{Giriş}

Termik santrallerde yanmamış karbon, kömürde depolanan kimyasal enerjinin tam olarak iletim ara maddesine verilmemesiyle oluşan kısmıdır ve bu kimyasal enerjiden tam olarak faydalanılamaması anlamına gelmektedir. Yanmamış karbon miktarı gerek uçucu külde gerekse kazan altı küllerde yanma rejimine ve yanma verimliliğine bağlı olarak değişmektedir. Yanmamış karbonun küllerin bünyesinde bulunması hem işletme olarak termik santralin elde edilebilecek nihai enerji miktarında bir kayı hem

\footnotetext{
*Sorumlu yazar: mehmetubilen@yandex.com, mehmet.bilen@beun.edu.tr Geliş Tarihi: 08.01.2020, Kabul Tarihi: 16.07.2020
} 
de küllerin değerlendirilebilirliği anlamında bir yetersizlik olarak ortaya çıkmaktadır. Külün içerdiği yanmamış karbon oranı birçok nedene bağlıdır [1]. Bunlar;

- Kömürün cinsi,

- Yakma kazanın dizaynı,

- Yakma şartları,

- Emisyon indirgeme teknolojileridir.

Enerji santrallerinde külde yanmamış karbon farklı miktarlarda olabilmektedir. Uçucu küldeki yanmamış karbon, termik santrallerde yakma verimini yansıtan önemli bir veridir [2]. Yanmamış karbon miktarları uçucu küllerde genelde daha fazladır ancak bu miktar yakma rejimine bağlı değişim göstermektedir. Bartonova [3] çalışmasına göre bitümlü kömürle çalışan bir santralde, yatak külünde yanmamış karbon miktarı \%1.23 iken uçucu külde yanmamış karbon miktarı \%5.57 olarak bulunmuştur. Deneysel ya da bilgisayımsal yollarla yanmamış karbon tahmin sistemi geliştirmek için birçok yaklaşım mevcuttur [4]. Moron [5] uçucu küldeki yanmamış karbonun, kömür karışımı için beslenen fazla hava oranıyla ilişkisini araştırmıştır [6]. Bartonava [3] çalışmasına göre yanmamış karbon miktarı, kömürün kimyasal kompozisyonundan, kömür petrografik özelliklerinden, kömür hazırlama yöntemlerinden gibi kömüre ait parametrelerle; yanma odası sıcaklığı, fazla hava miktarı, kazan içi kalma süresi gibi kazan dizaynına ait parametrelerle ilişkilidir [7, 8, 9, 10, 11]. Yanmamış karbon çeşitli fiziksel özellikler göstermektedir.

Şekil 1 ve Şekil 2'de küllerde bulunan yanmamış karbonun tipik doğası gösterilmiştir [1]. Küller kullanım potansiyeline göre ekonomik olarak düşük değerli olurlar ve bu tür küller uçucu madde giderme işlemi sırasında yumuşamazlar. Bu özelliklerinden dolayı keskin hatlı özelliklere sahip yanmamış karbon taneciklerine sahip olurlar. Diğer yandan bazı küller ise tam tersi olarak uçucu madde giderme işlemi sırasında yumuşama gösterirler. Bundan dolayı bu tür kömürlerden oluşan yanmamış karbon taneciklerinde "blow-holes" olarak adlandırılan delikler bulunmaktadır [1].

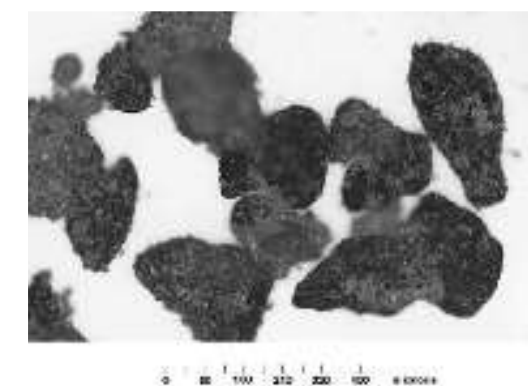

Şekil 1. Külde bulunan yanmamış karbon tanecikleri $(180<d<355 \mu \mathrm{m})[1]$
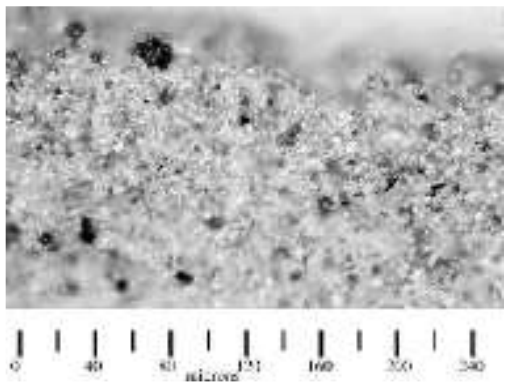

Şekil 2. Külde bulunan yanmamış karbon tanecikleri $(d<45 \mu \mathrm{m})[1]$

Uçucu küllerdeki tüm yanmamış karbon örneklerinin tanecik boyutu $100 \mu \mathrm{m}$ altında bulunmaktadır. Yanmamış karbonlar amorf bir yapıya sahiptir. Yanmamış karbon örneklerinin oluşum yoğunluk değerleri $0,15 \mathrm{gr} / \mathrm{cm}^{3}$ civarındadır. Yanmamış karbon hafif bir malzemedir

Yanmamış karbon diğer karbon türleriyle karşılaştıııldığı zaman içerisinde ihtiva ettiği uçucu madde miktarının daha farklı olduğu görülür. Yanmamış karbon içinde bulunan uçucu madde miktarı, siyah karbon ve kalsine koka yakın miktarda, aktif karbondakinden ise daha az miktarda bulunmaktadır. Bu nedenle yanmamış karbonun tek başına yanması zordur. Karbon içerisindeki uçucu maddeler büyük oranda küçük yüzey gruplarına sahip, tam olarak karbonize olmamış hidrokarbonlar içerir [1].

$\mathrm{Bu}$ çalışma kapsamında iki ayrı santralden alınan veriler incelenmiş ve kömüre ait parametrelerle uçucu kül bünyesindeki yanmamış karbon miktarları ilişkilendirilmiştir. İlk santral farklı uçucu madde içeren 17 adet kömürün yakıldığı süreçte incelenmiş ve bu süreçte toplanan uçucu küllerin yanmamış karbon miktarları tayin edilmiştir. İlk santralde yapılan bu gözlem, 17 farklı kömürün yakıldığı süreçte operasyonel koşulların benzerlik taşıdığı varsayımıyla gerçekleştirilmiştir. Çalışmanın ikinci kısmında ise 2 ayrı ünitesi olan termik santralden değirmen çıkışlarından alınan ögütülmüş kömür örnekleri boyut açısından incelenmiş ve boyut parametreleriyle külde yanmamış karbon miktarları ilişkilendirilmiştir. Burda amaç kazana vardiya boyunca beslenen kömür dağılımını belirlemek ve bu dağılıma ait boyut parametreleriyle yanmamış karbonu ilişkilendirmektir. Kömüre ait parametrelerin yanmamış karbon açısından etkisi literatür çalışmalarında vurgulanmaktadır ancak bu etkinin 
gözlemlenmesi ve sonuçların irdelenmesi literatürdeki eksiği tamamlaması da çalışmanın bir diğer amacını teşkil etmektedir.

\section{Materyal ve Metod}

Çalışma kapsamında iki farklı santralden kömür ve kül örnekleri alınmış ve birinci santralden alınan kömürlerin sadece uçucu maddeleri ikinci santralden alınan pulverize kömürlerin ise boyut dağılımları incelenmiştir. Alınan kül örnekleri ise yanmamış karbon açısından incelenmiştir.

\subsection{Birinci Santralden Alınan Kömür ve Kül Örnekleri}

Birinci santralden 17 farklı kömür örneği alınmış ve bunlar belli bir süreçte yakılmıştır. $\mathrm{Bu}$ süreçte operasyona ait parametrelerin sabit olduğu varsayılmış ve sisteme herhangi bir etki söz konusu olmamıştır. Toplanan bu kömürler uçucu madde içeriği açısından incelenmiştir. Kömür örneklerinin uçucu madde içerikleri analizi ASTM D 3175-07 [12] standardına uygun şekilde gerçekleștirilmiştir. Kömürler santralde yakıldıktan sonra, yakılan kömüre karşılık gelen kül (uçucu kül) örnekleri toplanmıştır ve yanmamış karbon içeriği açısından incelenmiştir. Yanmamış karbon analizleri ise ASTM D7348-13 [13] yöntemi izlenerek yapılmıştır.

Kömür örneklerinde uçucu madde içeriği kuru bazda yapılmıştır. Ancak kömür örneklerinin nem içeriklerine göre orijinal kömürlerin uçucu madde içerikleri farklılaşabilmektedir. Santrale kömürler orijinal halleriyle beslenmekte ve boyut küçültme işlemlerinden sonra kazanda yanmaktadır. Kömürde uçucu madde içeriği kadar nem varlığı da kazan içinde yanmada ve kazan öncesi süreçlerde etkindir. Dolayısıyla, yapılacak yanmamış karbon ve uçucu madde kıyaslamalarında hem orijinal bazda hem de kuru bazda uçucu madde içeriğini ayrı ayrı değerlendirmek gerekmektedir. Çünkü uçucu maddelerin kömürden uzaklaşmasından önce nem kömürden uzaklaşır. Bu da enerji alan bir süreçtir. Kömürün yanması için verilen enerji toplamı, hem nemi hem de uçucuları uzaklaştırmak için kullanılır daha sonrasında da kömür yanmaya başladıkça enerji vermektedir. Kazan içi sistemi küçülterek bir parça kömürün yandığını düşünecek olursak, o parça kömürün tam yanması için verilecek enerji miktarı nem ve uçucu madde içeriği arttıkça artacaktır. Kazan içindeki bütün kömür parçacıkları için aynı gerçek söz konusudur.

\section{2. İkinci Santralden Alınan Kömür ve Kül Örnekleri}

İncelenen ikinci santral iki ayrı üniteden oluşmaktadır. Örnekler değirmen çıkışından, elektrostatik filtre (ESP) sıralarından ve uçucu kül silolarından her vardiyada dış bir müdahalenin en az olduğu bir süreçte üç gün boyunca alınmıştır. 2. ünite ve 3. ünite için numune alma noktaları ve numune alma sıklıkları Tablo 1'de yer almaktadır.

•Kömür stok sahasından alınan yaklaşık 1 ton kömürün standart örnek azaltma işlemleri takip edilerek yaklaşık 200 kilograma düşürülmüştür. Bu örnekte kömürün kısa analiz değerlendirilmesi yapılmıştır.

-Değirmen çıkışı numuneleri vardiya başında ve vardiya ortasında olmak üzere her vardiyada iki kez 'burner' denilen ve numune almanın havayla gerçekleştiği düzenek yoluyla alınmıştır. Pulverize kömür numunelerinin alınmasıyla paralellik gösteren uçucu kül numunelerinin alınması analizler ve kıyaslamalar için önemlidir.

-Uçucu küller her vardiyada vardiya başı ve vardiya ortası olmak üzere iki kez alınmıştır.

Numune alımı akım şeması üzerinde numaralandırılmış noktalardan Tablo 1'de belirtilen sıklıklarda gerçekleştirilmiştir. Numunelerin alındığı süreçte santralde tek tip kömür kullanılmış ve santral sistemine müdahaleden olabildiğince kaçınılmıştır. 
Tablo 1. Üniteler için numune alma noktaları ve numune alma sıklıkları

\begin{tabular}{ll}
\hline Numune Alındığı Yer & Numune Alma Sıklığı \\
\hline Kömür Stok Sahası & Temsili numune alma \\
Değirmen Çıkışı (Pulverize Kömür) & $\begin{array}{l}\text { Her vardiyada her değirmen çıkışından vardiya başı ve vardiya ortası } \\
\text { olmak üzere iki defa numune alınmıştır. }\end{array}$ \\
Uçucu Kül & $\begin{array}{l}\text { Her vardiyada 2 kez olmak üzere numune alınmıştır. Her sıradan 1. } \\
\text { sıra, 2. sıra, 3. sıra, 4. sıra ve 1. ve 3. silolardan numune alınmıştır. }\end{array}$ \\
\hline
\end{tabular}

Şekil 3'de ikinci santrale ait örnek alma noktaları gösterilmektedir.

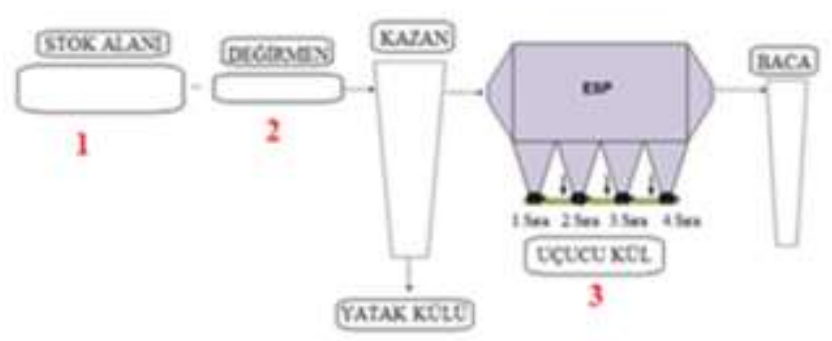

Şekil 3. İkinci santrale ait örnek alma noktaları

Kazana beslenen kömürün boyut dağılımını belirleyerek, boyut dağılımının etkisini anlamak üzerine çalışma yapılması planlandığı için çok sayıda numune ile çalışılmıştır. Değirmen çıkışından alınan pulverize kömür örnekleri Malvern Mastersizer S 2000 cihazıyla çalışılıış ve her bir vardiyada kazana beslenen kömürün boyut ortalamaları elde edilmiştir.

Boyut analizleri Malvern Mastersizer S 2000 cihazıyla yapılmış ve cihazın sağladığı 5 boyut parametresinin incelenmesi amaçlanmıştır. Bu boyut parametreleri ve anlamları;

$\mathrm{D}_{10}$ : Numunenin \%10'unun geçtiği boyut $(\mu \mathrm{m}), \mathrm{D}_{50}$ : Numunenin \%50'unun geçtiği boyut $(\mu \mathrm{m}), \mathrm{D}_{90}$ : Numunenin \%90'unun geçtiği boyut $(\mu \mathrm{m}), \mathrm{D}_{32}$ : Hacim-yüzey ortalama çap (Sauter ortalamas1)

$$
D_{32}=\frac{\sum_{1}^{n} D_{i}{ }^{3} v_{i}}{\sum_{1}^{n} D_{i}{ }^{2} v_{i}}
$$

$\mathrm{D}_{43}$ : Hacim-ağırlık ortalama çap (DeBroukere ortalaması)

şeklindedir.

$$
D_{43}=\frac{\sum_{1}^{n} D_{i}{ }^{4} v_{i}}{\sum_{1}^{n} D_{i}{ }^{3} v_{i}}
$$

Değirmen çıkışlarından alınan numunelerde her bir değirmene ait 4 brülörden çıkan numunelerle birlikte vardiyada; vardiya başı ve ortası olmak üzere alındığından ve 6 değirmen olduğundan 48 numune ile çalışılmıştır. Değirmen çıkışlarından numuneler 9 vardiya boyunca 2. ünite ve 3. üniteden alınmıştır. Uçucu kül örnekleri yanmamış karbon içeriğini bulmak üzere yakılmış ve yanmamış karbon analizleri gerçekleştirilmiştir.

\section{Sonuçlar}

Bu kısımda her bir santral için elde edilen sonuçlar ayrı ayrı ele alınmıştır.

\subsection{Birinci Santral}

Birinci santralde tek bir ünite mevcuttur ve $55 \mathrm{MW}$ güç üretilmektedir. Bu santrale bir süreç içinde beslenen 17 kömür örneği uçucu madde içerikleri tespit edilmiştir. Bu kömürlerin uçucu madde içerikleri Tablo 2'de verilmiştir. 
Tablo 2. Birinci santrale beslenen 17 farklı kömür örneğine ait uçucu madde içerikleri (Yılmaz 2019).

\begin{tabular}{|c|c|c|c|c|c|c|c|c|c|}
\hline Kömür Örneği No & 1 & 2 & 3 & 4 & 5 & 6 & 7 & 8 & 9 \\
\hline $\begin{array}{c}\text { Uçucu Madde } \\
\text { İçeriği (\%) (Orj. } \\
\text { Kömür) }\end{array}$ & 23.42 & 32.96 & 30.14 & 30.31 & 34.24 & 33.56 & 34.1 & 33.55 & 30.84 \\
\hline $\begin{array}{c}\text { Uçucu Madde } \\
\text { İçeriği (\%) (Kuru } \\
\text { Kömür) }\end{array}$ & 25.48 & 37.02 & 33.16 & 31.26 & 38.07 & 37.81 & 38.5 & 37.69 & 34.06 \\
\hline Kömür Örneği No & 10 & 11 & 12 & 13 & 14 & 15 & 16 & 17 & \\
\hline $\begin{array}{c}\text { Uçucu Madde } \\
\text { İçeriği (\%) (Orj. } \\
\text { Kömür) }\end{array}$ & 31.21 & 31.82 & 31.59 & 33.17 & 32.6 & 32.05 & 32.32 & 30.39 & \\
\hline $\begin{array}{c}\text { Uçucu Madde } \\
\text { İçeriği (\%) (Kuru } \\
\text { Kömür) }\end{array}$ & 34.55 & 35.98 & 35.62 & 36.77 & 36.84 & 36.03 & 36.29 & 31.79 & \\
\hline
\end{tabular}

$\mathrm{Bu}$ santrale incelen kömür örneklerinin yakılmasıyla elde edilen kül örnekleri yanmamış karbon açısından incelenmiş ve sonuçlar Tablo 3 'de verilmiştir.

Tablo 3. Birinci santrale beslenen 17 farklı kömür örneğine ait uçucu madde içerikleri (Yılmaz 2019).

\begin{tabular}{cccccccccc}
\hline $\begin{array}{c}\text { Karşılık Gelen Kül } \\
\text { Örneği No }\end{array}$ & $\mathbf{1}$ & $\mathbf{2}$ & $\mathbf{3}$ & $\mathbf{4}$ & $\mathbf{5}$ & $\mathbf{6}$ & $\mathbf{7}$ & $\mathbf{8}$ & $\mathbf{9}$ \\
\hline Yanmamış Karbon (\%) & 16.31 & 5.79 & 8.95 & 5.99 & 4.89 & 3.31 & 2.52 & 2.72 & 8.55 \\
\hline $\begin{array}{c}\text { Karşılık Gelen Kül } \\
\text { Örneği No }\end{array}$ & $\mathbf{1 0}$ & $\mathbf{1 1}$ & $\mathbf{1 2}$ & $\mathbf{1 3}$ & $\mathbf{1 4}$ & $\mathbf{1 5}$ & $\mathbf{1 6}$ & $\mathbf{1 7}$ \\
\hline Yanmamış Karbon (\%) & 4.92 & 5.71 & 5.22 & 4.88 & 3.92 & 3.28 & 3.65 & 6.22 \\
\hline
\end{tabular}

Tablo 2 ve Tablo 3'de elde edilen birleştirilerek yanmamış karbonun uçucu madde ile olas1 ilişkileri belirlenmiştir. Şekil 4 ve Şekil 5'de bu ilişkiler gösterilmiştir.

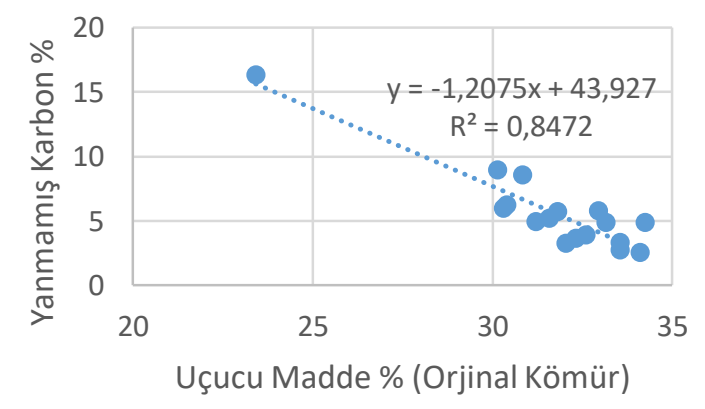

Şekil 4. Uçucu Madde (Orj. Baz) (\%) ve yanmamış karbon $(\%)$.

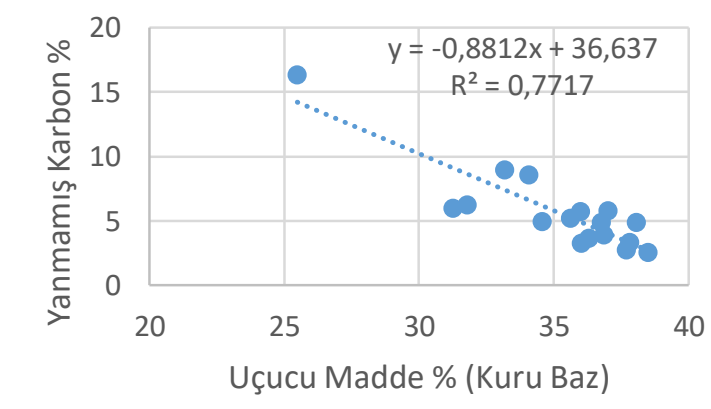

Şekil 5. Uçucu Madde (Kuru Baz) (\%) ve yanmamış karbon $(\%)$.

Şekil 4 ve Şekil 5 incelendiğinde yanmamış karbon miktarı kömürün uçucu madde içeriğiyle önemli ölçüde ilişkilidir. Orijinal kömür örnekleriyle 0.84 olan ilişki katsayısı kuru kömür örneklerinde 0.77 olarak bulunmuştur. Bunun sebebi ise kömürün nem içeriğinin de yanmamış karbon miktarında etkili olduğu gerçeği olarak düşünülmektedir.

\section{2. İkinci Santral}

\subsubsection{Kısa Analiz}

Stok sahasından alınan örnek menşei Kolombiya olan 170000 tonluk kömürü temsil eden bir numunedir. Stok sahasından alınan örneğin kısa analizi yapılmış ve Tablo 4'de verilmiştir. 
Tablo 4. Stok sahasından alınan kömürün kısa analiz sonuçları.

\begin{tabular}{lcc}
\hline Analiz & Kuru Kömür & Orijinal Kömür \\
\hline Nem (\%) & - & 14,63 \\
Kül (\%) & 9,52 & 8,13 \\
Uçucu Madde Miktarı (\%) & 27,49 & 24,71 \\
Sabit Karbon (\%) & 51,89 & 46,64 \\
Toplam Kükürt (\%) & 0,44 & 0,40 \\
Üst Isıl Değer (Kcal/kg) & 6628 & 5958 \\
Alt Isıl Değer (Kcal/kg) & 6403 & 5755 \\
\hline
\end{tabular}

Numune orijinal bazda \%8.13 kül, \%24.71 uçucu madde, \%46.64 sabit karbon içermektedir. Numunenin üst 1 sıl değeri $5958 \mathrm{kcal} / \mathrm{kg}$ ' dır. Nem miktarının \%14 civarında olması numunenin şubat aylarında temin edilmesi ve numune sürecindeki hava koşullarının etkisi olduğu söylenebilir. Kısa analizleri yapılan kömürün alt bitümlü kömür olduğu tespit edilmiştir.

\subsubsection{Değirmen Çıkışlarından Alınan Kömür Örneği Çalışmaları}

Değirmen çıkışlarından her vardiyada, vardiya başı ve vardiya ortası olmak üzere iki kez örnek alınmıştır ve alınan bu örneklerin ayrı ayrı boyut dağılımları belirlenmiştir [14]. Tablo 5'de örnek bir vardiyaya ait değirmen çıkışı numunelerinin örnek bir vardiyaya ait analiz sonuçları verilmiştir.

Tablo 5. Değirmen çıkışı numunelerinin örnek bir vardiyaya ait analiz sonuçları

\begin{tabular}{|c|c|c|c|c|c|c|c|c|c|c|c|}
\hline \multicolumn{6}{|c|}{ Tarih: 13.02.2013,Çarşamba, Saat:17:00 Ünite:2 } & \multicolumn{6}{|c|}{ Tarih: 13.02.2013, Çarşamba, Saat:21:00, Ünite:2 } \\
\hline \multicolumn{12}{|c|}{ (Ç17002a1:Çarşamba,1700, 2 ünite, A Değirmeni, 1.brülör) } \\
\hline $\begin{array}{l}\text { Numune } \\
\text { Kodu }\end{array}$ & $\mathbf{D}_{10}$ & $\mathbf{D}_{\mathbf{5 0}}$ & $D_{90}$ & $D_{32}$ & $D_{43}$ & $\begin{array}{l}\text { Numune } \\
\text { Kodu }\end{array}$ & $D_{10}$ & $D_{50}$ & $\mathbf{D}_{90}$ & $\mathbf{D}_{32}$ & $\mathbf{D}_{43}$ \\
\hline Ç17002a1 & 8.34 & 50.26 & 110.82 & 9.16 & 56.19 & Ç21002a1 & 14.73 & 75.42 & 166.30 & 11.37 & 84.66 \\
\hline Ç17002a2 & 8.02 & 59.55 & 150.96 & 8.49 & 71.27 & Ç21002a2 & 15.62 & 75.40 & 161.58 & 13.14 & 82.97 \\
\hline Ç17002a3 & 11.34 & 68.21 & 158.06 & 10.17 & 78.20 & Ç21002a3 & 6.11 & 43.16 & 105.21 & 6.96 & 50.64 \\
\hline Ç17002a4 & 8.10 & 49.86 & 114.75 & 8.73 & 57.22 & Ç21002a4 & 7.00 & 47.73 & 109.85 & 8.41 & 54.55 \\
\hline Ç17002b1 & 5.59 & 49.23 & 126.08 & 7.11 & 58.65 & Ç21002b1 & 12.56 & 78.84 & 190.89 & 10.14 & 92.43 \\
\hline Ç17002b2 & 5.90 & 53.24 & 128.96 & 7.70 & 61.35 & $\mathrm{C} 21002 \mathrm{~b} 2$ & 17.31 & 80.06 & 170.25 & 13.85 & 88.53 \\
\hline $\mathrm{C} 17002 \mathrm{~b} 3$ & 5.36 & 36.51 & 94.67 & 12.27 & 44.25 & Ç21002b3 & $*$ & $*$ & $*$ & $*$ & $*$ \\
\hline Ç17002b4 & 5.93 & 48.15 & 118.85 & 7.36 & 56.66 & Ç21002b4 & 8.37 & 60.10 & 137.69 & 9.56 & 68.23 \\
\hline Ç17002c1 & 9.59 & 54.05 & 120.25 & 9.11 & 60.91 & Ç21002c1 & 14.34 & 68.29 & 157.85 & 12.50 & 79.06 \\
\hline Ç17002c2 & 12.00 & 60.81 & 134.44 & 10.79 & 68.34 & Ç21002c2 & 14.04 & 67.79 & 151.43 & 12.19 & 76.76 \\
\hline Ç17002c3 & 2.84 & 21.27 & 65.28 & 4.04 & 28.80 & Ç21002c3 & 2.29 & 17.03 & 52.70 & 3.49 & 23.94 \\
\hline Ç17002c4 & 2.63 & 19.01 & 62.24 & 3.81 & 27.15 & Ç21002c4 & 6.37 & 49.98 & 125.20 & 7.44 & 59.26 \\
\hline Ç17002d1 & 5.01 & 39.23 & 123.20 & 6.26 & 53.37 & Ç21002d1 & 8.10 & 59.12 & 139.17 & 8.96 & 68.05 \\
\hline Ç17002d2 & 5.46 & 46.49 & 124.79 & 6.65 & 57.18 & Ç21002d & 13.35 & 69.07 & 146.81 & 12.86 & 76.19 \\
\hline Ç17002d 3 & 13.67 & 75.28 & 159.35 & 12.03 & 82.45 & Ç21002d 3 & 10.06 & 51.79 & 115.53 & 9.73 & 58.93 \\
\hline Ç17002d4 & 18.76 & 69.29 & 128.79 & 26.33 & 72.33 & Ç21002d4 & 12.98 & 68.10 & 148.35 & 11.82 & 75.93 \\
\hline Ç17002e1 & 0.58 & 5.42 & 41.09 & 1.59 & 15.13 & Ç21002e1 & 1.14 & 13.65 & 89.93 & 2.39 & 31.95 \\
\hline Ç17002e2 & 2.07 & 32.65 & 164.88 & 3.20 & 60.61 & Ç21002e 2 & 17.88 & 102.82 & 253.33 & 12.26 & 121.68 \\
\hline Ç17002e3 & 1.09 & 11.23 & 61.97 & 2.28 & 23.10 & Ç21002e3 & 7.45 & 59.74 & 154.48 & 7.55 & 72.31 \\
\hline Ç17002e4 & 1.12 & 11.02 & 57.93 & 2.29 & 21.84 & Ç21002e4 & 10.02 & 70.33 & 163.50 & 9.73 & 80.40 \\
\hline Ç17002f1 & 4.23 & 31.96 & 98.44 & 5.45 & 43.62 & Ç21002f1 & 8.79 & 64.25 & 149.97 & 6.28 & 73.51 \\
\hline Ç17002f2 & 3.95 & 41.00 & 130.50 & 5.25 & 55.60 & Ç21002f2 & 10.96 & 63.86 & 150.77 & 10.91 & 74.11 \\
\hline Ç17002f3 & 1.20 & 8.97 & 29.52 & 2.27 & 13.04 & Ç21002f3 & 9.04 & 41.26 & 102.40 & 17.19 & 49.56 \\
\hline Ç17002f4 & 4.63 & 28.89 & 81.96 & 5.73 & 38.45 & Ç21002f4 & 7.70 & 63.72 & 154.27 & 8.41 & 73.82 \\
\hline ortalama & 6.14 & 40.48 & 107.82 & 7.42 & 50.23 & ortalama & 10.27 & 60.50 & 143.36 & 9.87 & 70.32 \\
\hline
\end{tabular}

Boyut Analizleri Malvern Mastersizer S 2000 cihazıyla yapılmıştır. Mastersizer cihazı ile hazırlanan yaklaşık 800 numunenin analizleri su ortamında yapılmıştır.

Malvern Mastersizer cihazından alınan herhangi bir vardiyadaki örnek boyutlandırma sonuçları incelendiğinde ilgilenilen $\mathrm{D}_{10}, \mathrm{D}_{50}, \mathrm{D}_{90}, \mathrm{D}_{32}, \mathrm{D}_{43}$ değerleri görülmektedir. Bu boyut parametreleri $\mathrm{D}_{10}$, $\mathrm{D}_{50}, \mathrm{D}_{90}, \mathrm{D}_{32}, \mathrm{D}_{43}$ her bir numune için belirlenmiş ve her bir vardiyadaki kazana beslenen kömürlerin ortalama boyut parametreleri aritmetik olarak elde edilmiştir [14]. Bu analizler sonucunda Tablo 6'da 2. ve 3. ünitenin 9 vardiya boyunca ortalama boyut parametre sonuçları verilmiştir. Tablo 7 'de ise her 
bir üniteden 9 vardiya boyunca gözlemlenen yanmamış karbon değerleri tablolaştırılmıştır. Şekil 6 ve Şekil 7'de ise pulverize kömür örneklerinin boyut parametrelerinin değişimi 9 vardiya boyunca her iki ünite için verilmiştir.

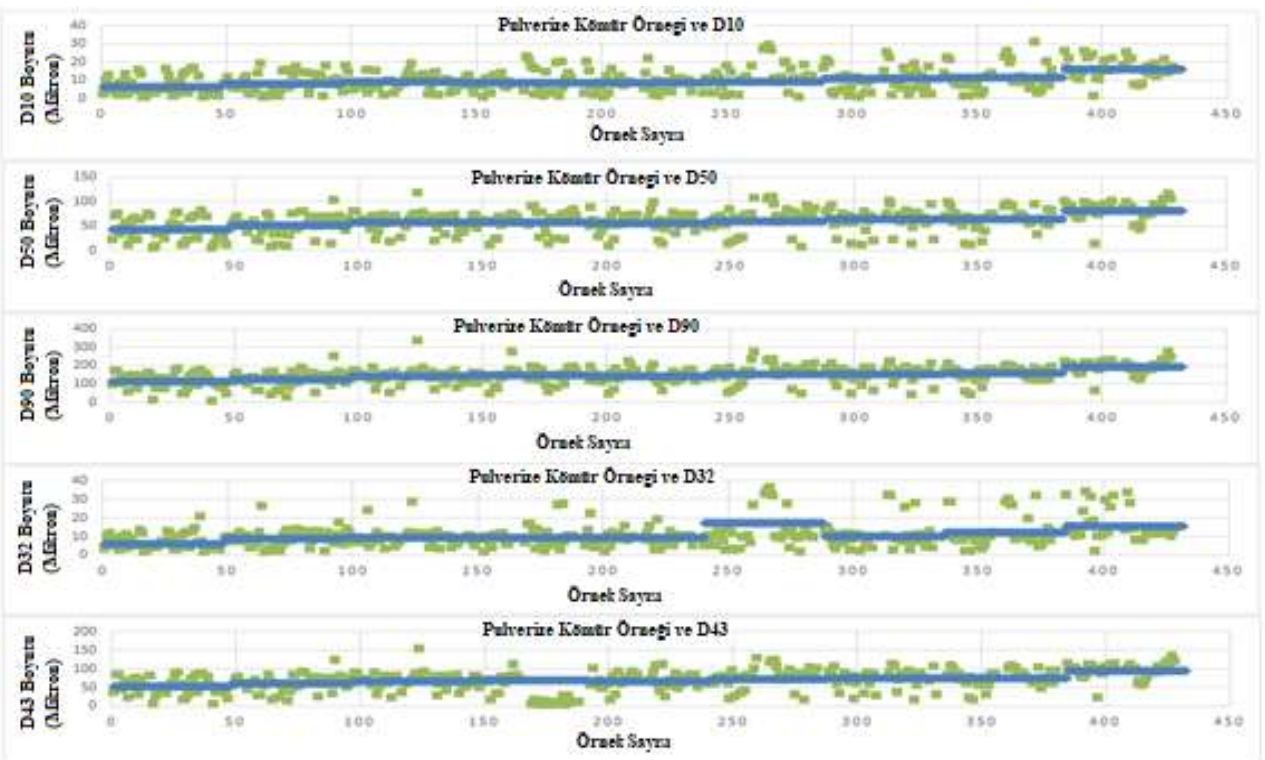

Şekil 6. Ünite 2 için 9 vardiya boyunca boyut parametrelerindeki değişim (Mavi çizgiler vardiya bazındaki ortalamaları göstermektedir) [15]

Tablo 6. 2. Ünite için 9 vardiya boyunca boyut parametre sonuçları [15]

\begin{tabular}{lllllll}
\hline$\ddot{\text { Ünite No }}$ & Vardiya No & $\mathbf{D}_{\mathbf{1 0}}(\boldsymbol{\mu m})$ & $\mathbf{D}_{\mathbf{5 0}}(\boldsymbol{\mu \mathbf { m }})$ & $\mathbf{D}_{\mathbf{9 0}}(\boldsymbol{\mu m})$ & $\mathbf{D}_{\mathbf{3 2}}(\boldsymbol{\mu \mathbf { m }})$ & $\mathbf{D}_{\mathbf{4 3}}(\boldsymbol{\mu \mathbf { m }})$ \\
\hline & 1. Vardiya & 6.38 & 42.06 & 114.44 & 6.02 & 52.72 \\
& 2. Vardiya & 8.21 & 50.49 & 125.6 & 8.65 & 60.28 \\
& 3. Vardiya & 9.16 & 56.79 & 141.3 & 9.26 & 67.56 \\
& 4. Vardiya & 8.74 & 57.34 & 147.95 & 9.2 & 69.14 \\
Ünite 2 & 5. Vardiya & 8.6 & 56.19 & 141.33 & 9.27 & 67.21 \\
& 6. Vardiya & 9.51 & 59.7 & 151.56 & 17.19 & 71.75 \\
& 7. Vardiya & 10.99 & 63.88 & 155.97 & 10.15 & 75.24 \\
& 8. Vardiya & 11.64 & 64.11 & 159.15 & 11.99 & 76.42 \\
& 9. Vardiya & 15.99 & 81.17 & 191.6 & 15.72 & 94.32 \\
\hline Ünite No & Vardiya No & $\mathbf{D}_{\mathbf{1 0}}(\boldsymbol{\mu} \mathbf{m})$ & $\mathbf{D}_{\mathbf{5 0}}(\boldsymbol{\mu} \mathbf{m})$ & $\mathbf{D}_{\mathbf{9 0}}(\boldsymbol{\mu} \mathbf{m})$ & $\mathbf{D}_{\mathbf{3 2}}(\boldsymbol{\mu} \mathbf{m})$ & $\mathbf{D}_{\mathbf{4 3}}(\boldsymbol{\mu} \mathbf{m})$ \\
\hline & 1. Vardiya & 9.09 & 56.19 & 137.88 & 9.01 & 66.42 \\
& 2. Vardiya & 7.69 & 50.13 & 125.57 & 10.92 & 59.72 \\
& 3. Vardiya & 9.08 & 51.18 & 123.84 & 11.13 & 60.23 \\
& 4. Vardiya & 11.48 & 61 & 144.42 & 9.49 & 70.95 \\
Ünite 3 & 5. Vardiya & 10.27 & 58.26 & 136.05 & 9.65 & 67.23 \\
& 6. Vardiya & 8.5 & 47.21 & 118.18 & 8.67 & 56.65 \\
& 7. Vardiya & 10.44 & 57.16 & 134.99 & 14.16 & 66.35 \\
& 8. Vardiya & 10.81 & 61.22 & 140.12 & 10.96 & 69.71 \\
& 9. Vardiya & 13.52 & 64.2 & 147.53 & 13.17 & 73.76 \\
\hline
\end{tabular}




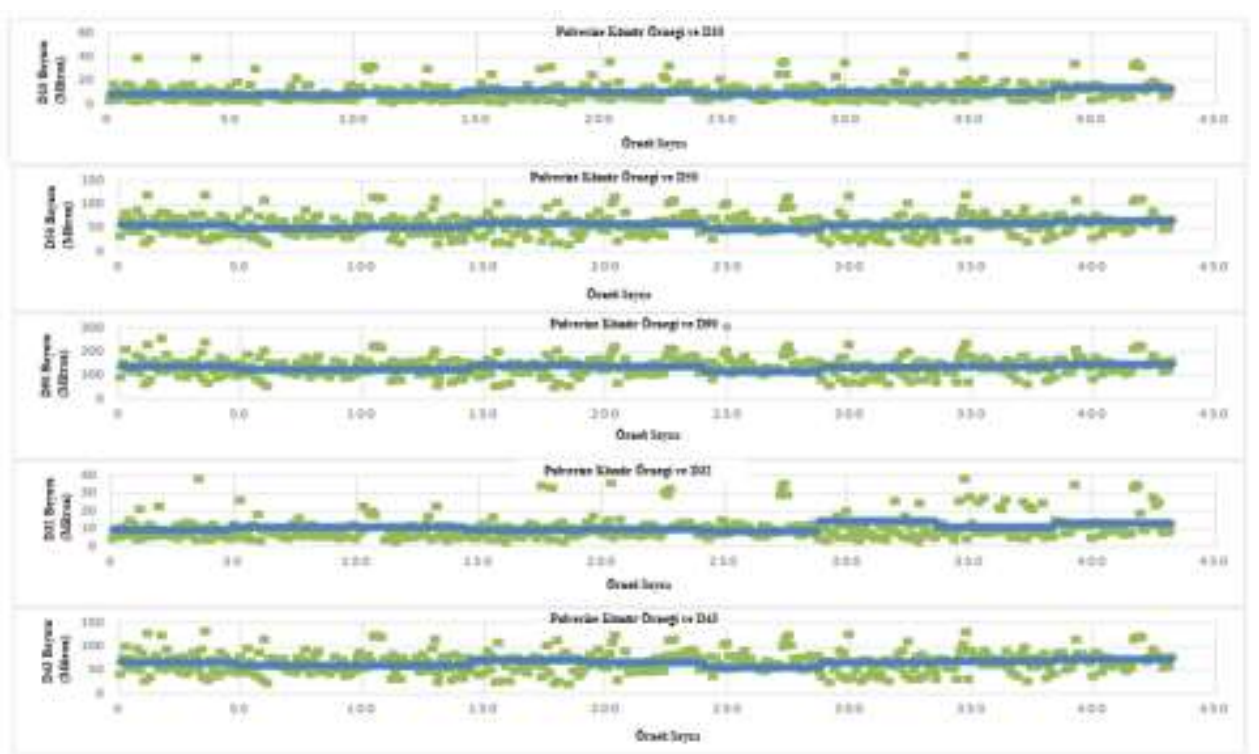

Şekil 7. Ünite 3 için 9 vardiya boyunca boyut parametrelerindeki değişim (Mavi çizgiler vardiya bazındaki ortalamaları göstermektedir) [15]

Tablo 7. İki ünite (2. ve 3. Ünite) için 9 vardiya boyunca gözlemlenen yanmamış karbon miktarları (\%) [15]

\begin{tabular}{|c|c|c|c|c|c|c|c|c|c|c|}
\hline & & $\begin{array}{c}1 . \\
\text { Vardiya }\end{array}$ & $\begin{array}{c}2 . \\
\text { Vardiya }\end{array}$ & $\begin{array}{c}3 . \\
\text { Vardiya }\end{array}$ & $\begin{array}{c}4 . \\
\text { Vardiya }\end{array}$ & $\begin{array}{c}5 . \\
\text { Vardiya }\end{array}$ & $\begin{array}{c}6 . \\
\text { Vardiya }\end{array}$ & $\begin{array}{c}7 . \\
\text { Vardiya } \\
\end{array}$ & $\begin{array}{c}8 . \\
\text { Vardiya } \\
\end{array}$ & $\begin{array}{c}9 . \\
\text { Vardiya }\end{array}$ \\
\hline $\begin{array}{l}\tilde{\delta} \\
\overline{0} \\
\simeq\end{array}$ & $\begin{array}{c}\text { Unite } \\
2\end{array}$ & 1.53 & 3.26 & 2.57 & 3.21 & 3.24 & 5.2 & 3.13 & 4.11 & 4.72 \\
\hline 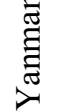 & $\begin{array}{c}\text { Unite } \\
3\end{array}$ & 1.44 & 2.5 & 3.08 & 2.68 & 1.79 & 1.5 & 4.84 & 3.27 & 4.58 \\
\hline
\end{tabular}

Şekil 8 ve Şekil 9' da ise her iki ünite için (sırayla 2. ve 3. ünite) pulverize kömür örneklerinin boyut parametreleri ile 9 vardiya boyunca küllerde gözlemlenen yanmamış karbon değerleri kıyaslanmıştır.

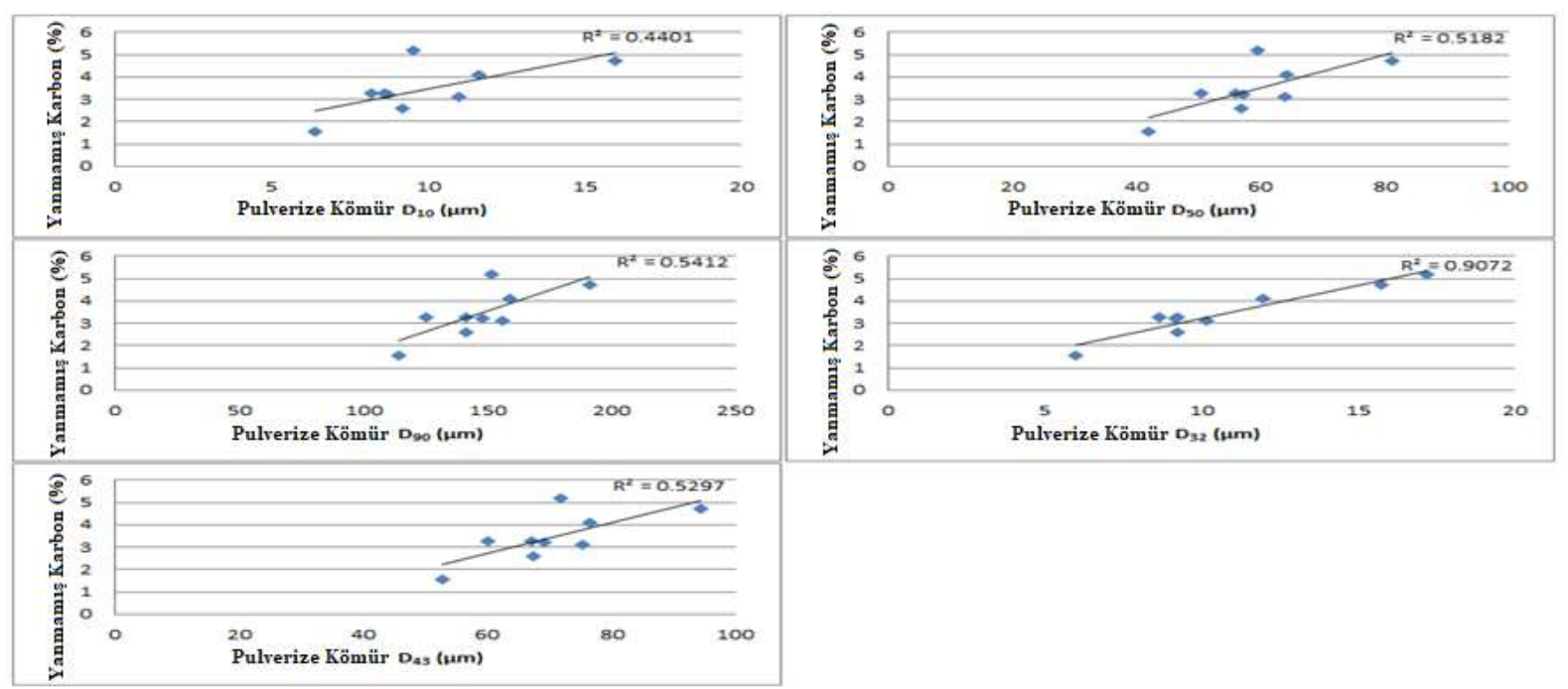

Şekil 8. Ünite 2 için 9 vardiya boyunca her bir boyut parametresinin $\left(\mathrm{D}_{10}\right.$. $\left.\mathrm{D}_{50}, \mathrm{D}_{90}, \mathrm{D}_{32}, \mathrm{D}_{43}\right)$ yanmamış karbon (\%) miktarıyla ilişsisi [15] 


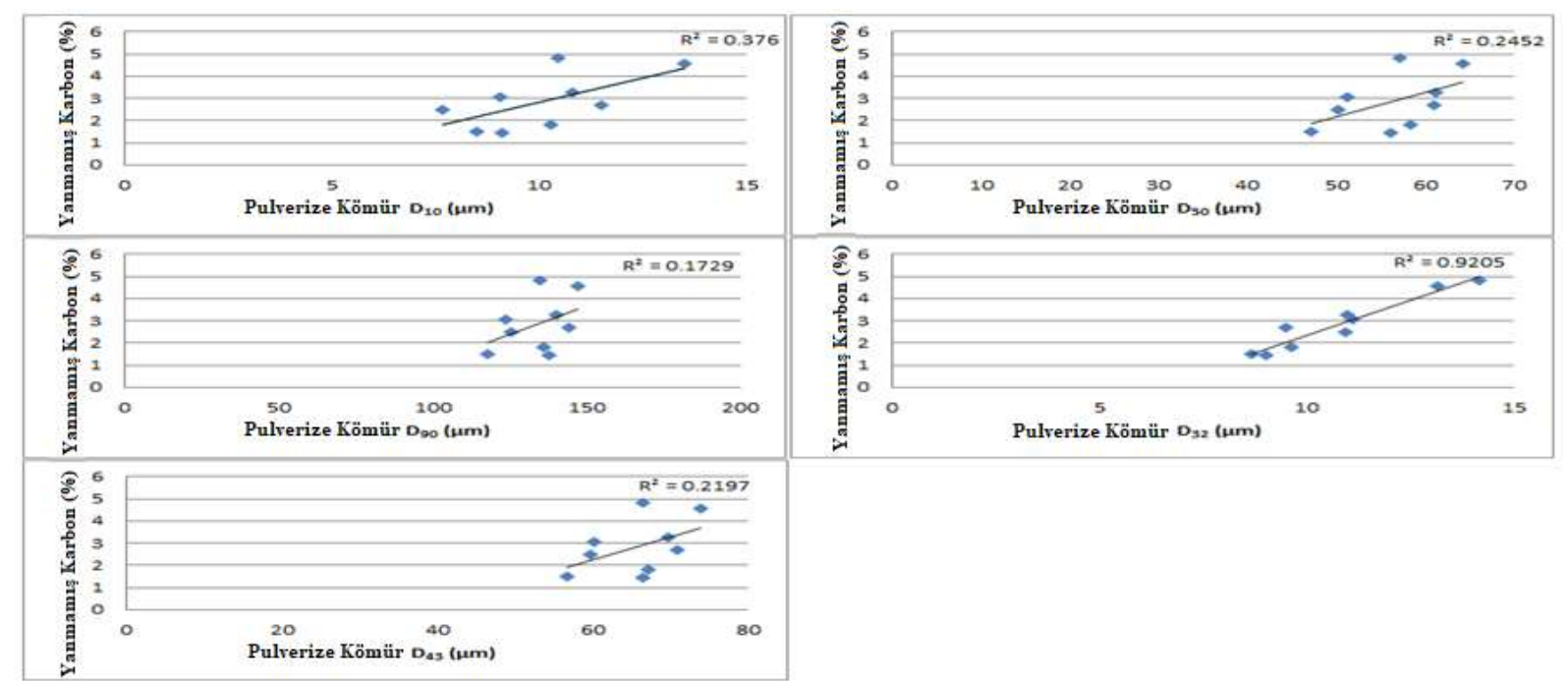

Şekil 9. Ünite 3 için 9 vardiya boyunca her bir boyut parametresinin $\left(D_{10} . D_{50}, D_{90}, D_{32}, D_{43}\right)$ yanmamış karbon (\%) miktarıla ilişkisi [15].

Şekil 8 ve 9 incelendiğinde, kömür boyut parametreleriyle kazanda yanarak elde edilen kül örneklerindeki yanmamış karbon miktarlarının ilişkili olduğu gözlemlenmiştir. Özellikle $\mathrm{D}_{32}$ parametresi her iki ünite için de 0.90 mertebesinde bir ilişki katsayı göstermiştir. 2 no'lu ünite için boyut parametreleri ile külde yanmamış karbon daha anlamlı ilişkiler göstermiş̧ir.

\section{Tartışma ve Değerlendirme}

Bu çalışma kapsamında, iki farklı santral farklı kömür özelliklerinin yanmamış karbon üzerinde etkisi araştırılarak incelenmiştir. Bu kapsamda ilk santralden 17 farklı kömür örneği ve bunların yanması sonucu oluşan 17 kül örneği toplanmıştır. Toplanan bu örnekler çalışmanın ilk aşamasında uçucu madde ile yanmamış karbon arasındaki ilişkinin tespiti için kömür örnekleri uçucu madde içeriği açısından kül örnekleri ise yanmamış karbon miktarları açısından incelenmiştir.

Elde edilen sonuçlara göre, yanmamış karbon miktarları sırasıyla kuru bazdaki uçucu madde içeriği ve orijinal kömürdeki uçucu madde içeriğiyle anlamlı ilişkiler $\left(0.77\right.$ ve $0.84 ; R^{2}=0.77$ ve $\left.R^{2}=0.84\right)$ katsayılı ilişkiyle) vermiştir. İlişkiler gözlemlendiğinde uçucu madde içeriği arttıkça yanmamış karbonun azaldığı görülmektedir, bu da kömürün uçucu maddesinin yanma sırasında kömürün tam yanmasına yardımcı olduğuyla açılanabilir. Yanma sırasında uçucu madde uzaklaşırken kömür daha gözenekli hale gelmekte ve oksijen daha kolay kömürün içyapısına kadar nüfus edebilmektedir. Kuru bazda daha düşük olan ilişkinin nedeni kömürün nem içeriğinin de yanmamış karbon miktarında etkili olabileceğini düşündürmektedir. Kömür nem içeriği kömürün ilk 1sınması sırasında ilk uzaklaşan kısımdır ancak bunda da nispeten bir enerji gerekir. Dolayısıyla kömürün tam yanması için gereken enerjinin küçük bir kısmı da olsa nem içeriğinin uzaklaşması için kullanılmakta ve yanma nispeten tamamlanmamış olarak kalmaktadır.

Çalışmanın ikinci kısmında ise, iki farklı üniteyle enerji üretimi yapan yerel bir santral çalışılmıştır. Bu santralden alınan ögütülmüş ya da diğer bir deyişle pulverize kömür örnekleri boyut dağılımları elde edilmiş ve her bir numuneye ait boyut parametreleri belirlenmiştir. Kazanda yanan kömürü temsil etmek amacıyla çok sayıda pulverize kömür örneği alınmış ve vardiya bazında boyut parametreleri ortalamaları belirlenmiştir. Her bir vardiyada yanma sonucu oluşan uçucu kül örnekleri de toplanmış ve yanmamış karbon içerikleri tespit edilmiştir. Elde edilen kömüre ait boyut parametresi sonuçları ile yanmamış karbon miktarları kıyaslanmıştır. Kıyaslamalar özellikle $\mathrm{D}_{32}$ boyut parametresinin yanmamış karbon miktarlarıyla anlamlı sonuçlar verdiğini göstermiştir. $\mathrm{D}_{32}$ boyut parametresi tanımlandığı şekliyle kömürlerin hacim yüzey ortalamasıdır. Dolayısıyla bu boyut parametresi ile yanmamış karbon arasında ilişki olması normaldir, çünkü kömür parçacıklarının 
yüzeyleri büyüdükçe ve hacimleri azaldıkça daha iyi yanacakları bilinmektedir. Düşük $\mathrm{D}_{32}$ değerlerinde düşük yanmamış karbon miktarının olması da bu yüzden anlaşılabilir bir durumdur.

Bu çalışmayla termik santral enerji verimliliği dikkate alındığında kömüre ait parametrelerin etkisi daha iyi bilinecektir. Elde edilen sonuçların, gerek konu ile ilgili araştırmacılar için gerekse santral operatörleri için faydalı olacağı düşünülmektedir.

\section{Yazarların Katkısı}

Mehmet BİLEN pulverize kömürlerin boyut parametreleri ile yanmamış karbon arasındaki ilişkilerin araştırılmasında katkıda bulunmuştur. Mehmet BİLEN deneysel olarak pulverize kömürlerin boyut parametrelerini belirlemiş ve küllerde yanmamış karbon tayinini gerçekleştirmiştir. Serdar YILMAZ ise kömürlerin uçucu madde içeriği ile yanmamış karbon arasındaki ilişkileri araştırmıştır ve bu kapsamdaki deneyleri yapmıştır. Deneyler için gerekli koşulların sağlanması Serdar YILMAZ yürütücülügünde, her iki konuya ait deneysel verilerin yorumlanması ise Mehmet BİLEN yürütücülüğünde gerçekleşmiştir.

\section{Çıkar Çatışması Beyanı}

Yazarlar arasında herhangi bir çıkar çatışması bulunmamaktadır.

\section{Araştırma ve Yayın Etiği Beyanı}

Yapılan çalışmada araştırma ve yayın etiğine uyulmuştur.

\section{Kaynaklar}

[1] Volkan S. 2006. Afşin-Elbistan termik santrali uçucu küllerinden yanmamış karbonun geri kazanımı. Yüksek Lisans Tezi, Çukurova Üniversitesi, Fen Bilimleri Enstitüsü, Adana.

[2] Yan W., Li J. 2009. Modelling of the unburned carbon in fly ash. EPE, 1: 90-93.

[3] Bartonova L., Klika Z., Pears D.A. 2006. Characterization of unburned carbon from ash after bituminous coal and lignite combustion in CFBs. Fuel, 86: 455-463.

[4] Pallarés J., Arauzo I., Teruel E. 2009. Development of an engineering system for unburned carbon prediction. Fuel, 88: 187-194.

[5] Moroń W. 2007. In combustion characteristics of blended coals, third European combustion meeting, Proceedings of the European Combustion Meeting: United Kingdom. 10.1094/PDIS91-4-0467B

[6] Lee B.H., Eddings E.G., Jeon C.H. 2012. Effect of Coal Blending Methods with Different Excess Oxygen on Unburned Carbon and NOx Emissions in an Entrained Flow Reactor. Energy Fuels, 26: 6803-6814.

[7] Granite E., Pennline H. 2000. In: Proceedings of the technical sessions presented by the Conference on carbon on utility fly ash. May 16, 2000, Pittsburgh, USA.

[8] Li Y., Zhang J.S., Liu Q., Lu J.L., Yue G.X., Sarofim A.F., Beér J.M., Lee Y.Y., Eliasson B. 2001. A study of the reactivity and formation of the unburnt carbon in CFB fly ashes. Dev Chem Eng Mineral Process, 9: 301-312.

[9] Shibaoka M. 1986. Carbon content of fly ash and size distribution of unburnt char particles in fly ash. Fuel, 65: 449-450.

[10] Stubington J.F., Wang A.L.T. 2000. Unburnt carbon elutriation from pressurised fluidised bed combustion of Australian black coals. Fuel, 79: 1155-1160.

[11] Yilmaz S. 2019 The Relationship between Unburned Carbon Levels in Coal Combustion Ash and Volatile Matter Content in Coal. Combustion Science and Technology, 1-10.

[12] ASTM D3175-07, 2007. Standard Test Method for Volatile Matter in the Analysis Sample of Coal and Coke. ASTM International, West Conshohocken, PA, https://doi.org/10.1520/D317507.

[13] ASTM D7348-13, 2013. Standard Test Methods for Loss on Ignition (LOI) of Solid Combustion Residues. ASTM International, West Conshohocken, PA, https://doi.org/10.1520/D7348-13. 
[14] Bilen M. 2013. Eren Enerji Zonguldak Termik Santrali Küllerinin Yanmamış Karbon Bakımından Değerlendirilmesi. Yüksek Lisans Tezi, Bülent Ecevit Üniversitesi, Fen Bilimleri Enstitüsü, Zonguldak.

[15] Bilen M., Kizgut S. 2016. Modeling of unburned carbon in fly ash and importance of size parameters. Fuel Processing Technology, 143: 7-17. 